\title{
THREE-YEAR ASSESSMENT OF THE SPACE-TIME DYNAMICS OF BURNED FOREST IN THE BRAZILIAN AMAZON, STATE OF MATO GROSSO
}

\author{
E. de Souza ${ }^{\mathrm{a}, *}$, R. Beuchle ${ }^{\mathrm{a}}$, R. C. Grecchi ${ }^{\mathrm{a}}, \mathrm{F}$. Achard ${ }^{\mathrm{a}}$ \\ a Joint Research Centre - Ispra, Institute for Environment and Sustainability, Forest Resource and Climate Unit. Via E. Fermi 2749 \\ TP261VA 21027 - ISPRA, - Italy, eliana.de-souza@jrc.ec.europa.eu
}

KEY WORDS: Amazon rainforest, forest degradation, forest fire, image classification, segmentation

\begin{abstract}
:
The use of fire in tropics for land management and for forest clearing contributes to forest degradation and to carbon emissions in the atmosphere. Yet, a comprehensive understanding of the spatial and temporal dynamics of forest fires is needed to mitigate such impacts. The primary aim of this study is to map burned forest in Brazilian Amazon by means of an object-based classification applied on Landsat imagery. Our secondary aim is to understand the spatial and temporal dynamics of forest fires. For this, we compare the forest cover maps with the map of burned forest generated during the dry season. In our study we consider three consecutive bi-annual periods (2013-2014, 2014-2015, 2015-2016) over four sites, in Mato Grosso State. From Landsat-8 imagery acquired during May or June of each year we derived NDVI and fraction images (soil, vegetation and shade) in order to map the following land cover classes: intact forest, burned forest, forest regrowth and non-forest. In addition, we map the burned areas during the fire season for each year. Intact forest, initially covering $55 \%$ of the area has lost $3.4 \%$ of its area over the course of three years. The annual burning increased from 2.6\% to 5.9\%, from 2013 to 2015 . Within the annually burned areas, non-forest areas showed a lower percentage of burning, compared to forest areas, varying from $3.8 \%$ to $7.9 \%$, while amongst the forest classes, burned forest showed the highest percentage. Re-burning on a biannual period is more than double of re-burning on a thrice-year.
\end{abstract}

\section{INTRODUCTION}

Although a decrease in deforestation in the Brazilian Amazon has been observed in the last ten years (INPE, 2015), studies on the Amazon Forest have pointed out a constant high intensity of forest fires in the states of Pará, Rondônia and Mato Grosso (Miettinen et al. 2015; Morton et al., 2013; Sousa et al., 2013; Lima et al., 2012) which contribute to forest degradation.

Degraded and intensely burned areas result in a decrease to the tree crown cover and consequently in an increased exposure of the soil, as well as in a loss of biodiversity (Cochrane and Schulze 1993; Silva Monteiro et al, 2004).

Selective logging and forest fire are the main drivers of forest degradation in the Brazilian Amazon (Souza et al., 2013; Matricardi et al., 2010). Forest fires have been associated with land-use change processes, in which fire escapes from pasture management (Fanin and van der Werf, 2015; Cano-Crespo et al., 2014, Lima et al., 2012), with changes in the weather conditions due to severe droughts (Aragão et al., 2008). Forest fires have however been identified as non-correlated to unmanaged land (Morton et al., 2013).

The relationship between burning and land cover is not yet fully understood. The distinct spectral characteristics of burned scars allow the mapping of burned forest areas through the use of satellite imagery, hence, the primary aim of this study is to map burned forest for three consecutive years in the State of Mato Grosso, Brazilian Amazon (2013-2014-2015) by means of an object-based classification applied to recent Landsat imagery. Our secondary aim is to understand the spatial and temporal dynamics of the fire related to land cover.

\section{MATHERIAL AND METHODS}

\subsection{Data sets and classification}

The study was carried out for an area of $40,616 \mathrm{~km}^{2}$, located in an active deforestation frontier in south-eastern Mato Grosso State in the Brazilian Amazon (Figure 1). The area is composed of subsets of four neighbouring Landsat scenes, image reference (path-row) and respective areas of the sub-scenes are as follows: 1 - 225/69 (3,450 km²), 2 - 226/68 (12,368 km²), 3 - 226/69 $\left(12,031 \mathrm{~km}^{2}\right), 4$ - 227/68 $\left(12,776.4 \mathrm{~km}^{2}\right)$. We consider three consecutive bi-annual periods (2013-2014, 2014-2015, 20152016) in the land cover change for the study.

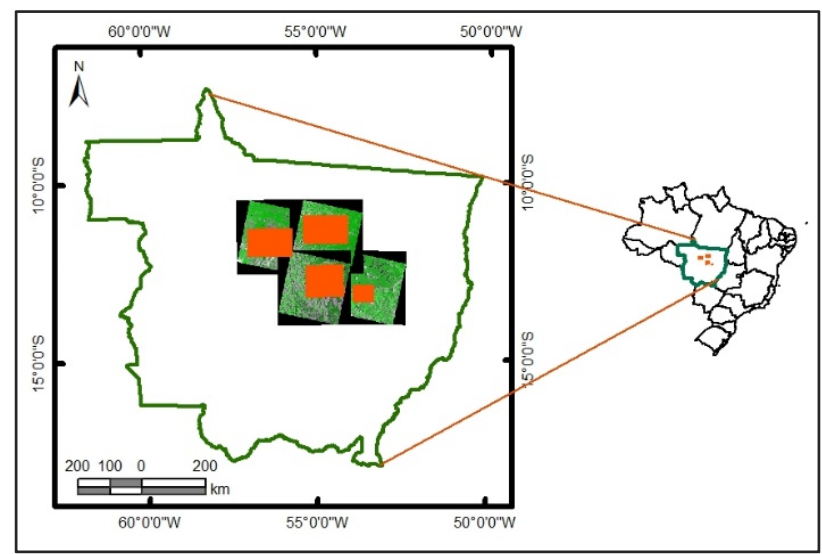

Figure 1. Study area in the State of Mato Grosso, Brazil.

A total of 64 scenes of Landsat-8 imagery, downloaded from the USGS archive, were processed. The visible (1, 2, and, 3), near infrared (4) and short-wave infrared (5 and 7) bands of each 
Landsat scene were used. Image processing was carried out using IMPACT software (Simonetti et al., 2016), which performed the image layer-stacking, clipping and, generated the NDVI (Normalized Difference Vegetation Index) and the soil, vegetation and shade fraction images, based on the linear spectral mixture model (Shimabukuro and Smith, 1991).

From images acquired on May or June of each year (beginning of the burning season), forest cover maps were produced with the following land cover classes: intact forest, burned forest, forest regrowth and non-forest. Burned areas were mapped during the early, middle and end of the dry season (i.e. July to November) of each year and the maps summed up to calculate the cumulative annual burning.

The segmentation was based on single date images with the same parameters applied for all dates. eCognition Developer 9.0 software (Benz et al., 2004) was used for segmenting and classifying the images. The classification of burned areas, as well as the land cover classification were threshold-based, using customized thresholds for each class and date. For classifying burned areas, the NDVI and the shade fraction images were used, while for the land cover classification, all fraction images (soil vegetation, shade) were used together with NDVI. Subsequently to the classification step, manual editing of the result was applied to ensure a high mapping accuracy.

The cumulative annual burning and the frequency of re-burning for bi-annual and thrice-year periods were calculated after overlaying the cumulative annual burning maps. Annual burned area maps were cross tabulated with respective maps of land cover of each year to relate burned areas to land cover. Changes in land cover over a three-year period were analysed by cross tabulating land cover information of 2013 and 2016. We analysed land cover changes of the entire study area and burned areas for the first year.

\section{RESULTS AND DISCUSSION}

The land cover maps generated for the years 2013, 2014, 2015 and 2016 show the majority of the area being covered by intact forest (Table 1). The forest area decreased from 54.9\% in 2013 to $51.5 \%$ on 2016 . This $3.4 \%$ of tree-cover loss $\left(758 \mathrm{~km}^{2}\right)$ has contributed to a $6.3 \%$ increase of non-forest areas, in addition to $2.6 \%$ of areas from regrowth and $0.3 \%$ from burned forest.

The annual burned areas increased from $2.6 \%$ on 2013 to $5.9 \%$ on 2015. The increase was higher from the first to second year (2.2\%) compared to the second to the third year (1.1\%). The total area burned $\left(3,940 \mathrm{~km}^{2}\right)$ represent $9.7 \%$ of the entire of this study. Miettinen et al. (2015) used a sampling approach to estimate the burning forest for the entire Amazon Biome within the Mato Grosso State for three dates in a five-year interval (2000-20052010). Similarly to what was found in the present study, these authors report a lower increase of burning for the second period (8.5\%) 2005 to 2010, compared to the first period (44.4\%) (20002005).

The present study mapped a total $1,087 \mathrm{~km}^{2}$ of intact forest disturbed by burning, in the course of three years (Table 2). This disturbed area, representing $4.9 \%$ of the total forest, which was much higher compared to what was found in the study of Matricardi et al. (2010), that conducted a detailed analysis of the relationship between selective logging and forest fire in an area on the Mato Grosso State during the period of 1992 to 2004. The findings of Matricardi et al. (2010) showed that fire alone was responsible for $2.9 \%$ of the forest disturbance, while combined effect of logging and forest fire resulted in a contribution of 5.5\% to forest disturbance.

The three years re-burning areas account for a total area of 5,381 $\mathrm{km}^{2}$ of land under fire at least once during the three years of analysis (Table 2). The analysis of burned areas by land cover class shows a predominance of fire in areas previously burned, burned forest and regrowth areas, with $39.8 \%$ and $23.4 \%$ of burned areas, respectively, in 2015. Non-forest areas showed relatively lower percentages of burning compared to intact forest.

\begin{tabular}{|c|c|c|c|c|}
\hline & 2013 & 2014 & 2015 & 2016 \\
\hline & \multicolumn{4}{|c|}{$\mathrm{km}^{2}$} \\
\hline Non-forest & 15,966 & 17,034 & 17,898 & 18,525 \\
\hline Forest burned & 601 & 204 & 551 & 506 \\
\hline Forest & 22,285 & 22,005 & 21,211 & 20,897 \\
\hline \multirow[t]{2}{*}{ Regrowth } & 1,765 & 1,374 & 957 & 688 \\
\hline & \multicolumn{4}{|c|}{$\%$} \\
\hline Non-forest & 39.3 & 41.9 & 44.1 & 45.6 \\
\hline Forest burned & 1.5 & 0.5 & 1.4 & 1.2 \\
\hline Forest & 54.9 & 54.2 & 52.2 & 51.5 \\
\hline Regrowth & 4.3 & 3.4 & 2.4 & 1.7 \\
\hline
\end{tabular}

Table 1 - Area of land cover classes and percentage of occurrence for the years 2013-2016.

Similar results were observed by Fanin and van der Werf (2015), comparing burning occurrence in the areas of forest and pasture during a ten-year period (2002-2012) on selected areas on Mato Grosso. These authors observed higher percentage of burning occurring in forest areas compared to non-forest (pasture) areas, with $7 \%$ and $8 \%$ for forest areas against 86 and $87 \%$ for pastures and forest during the years 2007 and 2010. This trend of higher burning on forest areas is an indication of fires being used for clearing areas more than for land management.

Lima et al. (2012) also observe a direct relation between fire and the process of land cover change, in a study for an area on the boarder of Rondônia and Mato Grosso `s States, with fire widely affecting previously degraded vegetation. Lima et al. (2012) reported 31\% of area burned in 2005 had been deforested in one of three preceding years.

\begin{tabular}{|lrrrr|}
\hline & 2013 & 2014 & 2015 & 3-years \\
\cline { 2 - 5 } Non-forest & \multicolumn{4}{c}{$\mathrm{km}^{2}$} \\
Forest burned & 71 & 1,151 & 1,410 & 2,042 \\
Forest & 176 & 383 & 219 & 246 \\
Regrowth & 187 & 324 & 224 & 1,087 \\
Total & 1,040 & 1,944 & 2,397 & 365 \\
& \multicolumn{4}{c}{$\%, 940$} \\
\cline { 2 - 5 } Non-forest & 3.8 & 6.8 & 7.9 & \\
Forest burned & 11.7 & 42.2 & 39.8 & 42.8 \\
Forest & 0.8 & 1.7 & 2.6 & 4.0 \\
Regrowth & 10.6 & 23.6 & 23.4 & 32.0 \\
Total & 2.6 & 4.8 & 5.9 & 9.7 \\
\hline
\end{tabular}

Table 2 - Area burned, by land cover class, and its percentage for the years 2013, 2014 and 2015 and, 3-years cumulative.

The frequency of re-burning over the three-year period accounts for $2.6 \%$ of the total area $\left(1,040 \mathrm{~km}^{2}\right)$. The percentage of reburning on biannual periods (2013-2014, 2013-2015 and 20142015) varied from $7.3 \%$ to $10.7 \%$ (Table 3 ). Over the three-year period, a total of $5,381 \mathrm{~km}^{2}$ were burned. From this cumulative burned area re-burned re-burning occurred at least once in the biannual periods. Twice re-burning accounts for $80.7 \%$ of the accumulated burned area, while a thrice re-burning was detected in $19.3 \%$ of the burned area. 
The analysis of non-forest areas show that approximately 50\% have been re-burned in a biannual or three-year period. This high percentage of re-burning on non-forest areas, compared with reburning in forest areas, can be related to fire been used for managing pastures. Regrowth areas show re-burning as varying from $15 \%$ to $19 \%$ while forest areas vary from $7 \%$ to $27 \%$ over the years examined. The percentage of burning recurrence on burned forest areas is $5 \%$ to $7 \%$, and thus lower if compared to regrowth and burned forest areas, reflecting the land cover class in which burning is less needed for clearing areas previously under fire (Table 3).

\begin{tabular}{|lcccc|}
\hline & 2013 & 2014 & 2013 & 3-years \\
\cline { 2 - 5 } & -2014 & -2015 & -2015 & \multicolumn{4}{c|}{$\mathrm{km}^{2}$} \\
Non-forest & 1,640 & 2,193 & 1,766 & 606 \\
Forest burned & 177 & 266 & 230 & 71 \\
Forest & 604 & 1,166 & 913 & 176 \\
Regrowth & 563 & 716 & 527 & 187 \\
Total & 2,984 & 4,341 & 3,437 & 1,040 \\
\cline { 2 - 5 } & & $\%$ & 51 & 58 \\
Non-forest & 55 & 51 & 6.7 & 6.8 \\
Forest burned & 5.9 & 6.1 & 6.7 \\
Forest & 20.2 & 26.9 & 26.6 & 16.9 \\
Regrowth & 18.9 & 16.5 & 15.3 & 18 \\
Total & 7.3 & 10.7 & 8.5 & 2.6 \\
\hline
\end{tabular}

Table 3. Frequency of re-burning for biannual period and for the 3-years period (2013, 2014 and, 2015) based on 2013 land cover map.

Although an annual increase of burned areas is observed, with 2015 burned areas $\left(2,397 \mathrm{~km}^{2}\right)$ being is more than double of the areas in $2013\left(1,040 \mathrm{~km}^{2}\right)$, a high variability is observed regarding the spatial distribution of re-burning in forest areas, as shown on the re-burning frequency (Table 3) with $16.9 \%$ for a three-year period and an average of $25 \%$ for a twice re-burning. The maps of annual burning and burning frequency (Figure 2) shows no spatial tendency on areas that have been re-burned twice or thrice.
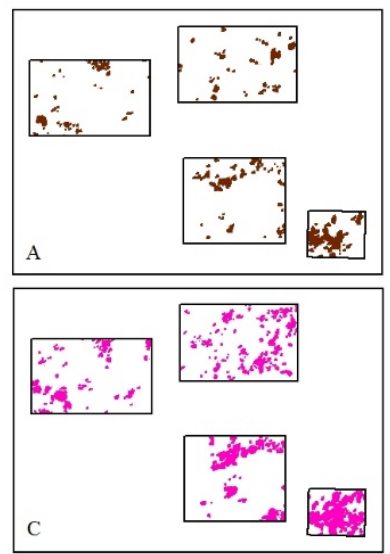

Figure 2 - Burning occurrence on: A) 2013, B) 2014, C) 2015 and, D) burning frequency (blue $=$ twice, red $=$ thrice).

The land cover change over the three-year period (Table 4) shows intact forest with $88.8 \%$ of its area in 2013 maintained as forest in 2016 , with $1.8 \%$ changing to burned forest and $8.5 \%$ to nonforest. The classes, regrowth and burned forest, are the classes most prone to land cover change. $50.6 \%$ of the regrowth areas of 2013 regenerated into forest, $28.9 \%$ turned into non-forest and $18 \%$ continued as a regrowth in 2016.

The burned forest class showed $35.5 \%$ of its total area recovering as forest, while around $26 \%$ of the area changed into regrowth or non-forest.

\begin{tabular}{|l|c|c|c|c|}
\hline \multirow{2}{*}{2013} & $\begin{array}{l}\text { Non- } \\
\text { forest }\end{array}$ & $\begin{array}{l}\text { Forest } \\
\text { burned }\end{array}$ & Forest & Regrowth \\
\cline { 2 - 5 } Non-forest & \multicolumn{4}{|c|}{$\%$} \\
Forest burned & 100 & 29.3 & 8.5 & 28.9 \\
Forest & & 9.6 & 1.8 & 2.5 \\
Regrowth & & 35.4 & 88.8 & 50.6 \\
\hline
\end{tabular}

Table 4. Area of land cover conversion from 2013 to 2016.

Table 5 shows areas that were burned in 2013, and the conversion of the class from 2013 to 2016. A restoration process is observed for burned forest and regrowth converting into forest (21.9\% and $16.8 \%$ respectively). Nevertheless, the percentage of areas that are converted from forest areas to non-forest is higher: to regrowth (55\%), followed by burned forest (39\%), and intact forest $(35.4 \%)$. These figures indicate the feasibility of clearing forest under different stage of preservation.

\begin{tabular}{|l|c|c|c|c|}
\hline $2013 \quad 2016$ & $\begin{array}{l}\text { Non- } \\
\text { forest }\end{array}$ & $\begin{array}{l}\text { Forest } \\
\text { burned }\end{array}$ & Forest & Regrowth \\
\cline { 2 - 5 } Non-forest & 100 & 39 & 35.4 & 55.2 \\
Forest burned & & 9.8 & 7.4 & 2 \\
Forest & & 21.9 & 44.8 & 16.8 \\
Regrowth & & 29.3 & 12.4 & 26 \\
\hline
\end{tabular}

Table 5. Area of land cover conversion from 2013 to 2016 over areas burned in 2013.

Further steps towards understanding the spatial dynamic of burning forest will consider the use of Sentinel-2 imagery to increase the temporal and spatial accuracy of mapping, as well as classify the burned forest in level of severity to estimation carbon emission.

\section{ACKNOWLEDGEMENTS}

The Brazilian Foundation Conselho Nacional de Desenvolvimento Científico e Tecnológico, of the Ministry of Science, Technology and Innovation of Brazil (CNPq), is gratefully thanked for granting a scholarship for the first author to develop this study.

\section{REFERENCES}

Aragão, L.E.O.C.; Malhi, Y.; Barbier, N.; Lima, A.; Shimabukuro, Y.; Anderson, L.; Saatchi, S. 2008. Interactions between rainfall, deforestation and fires during recent years in the Brazilian Amazonia, Philos. T. R. Soc. B, 363, 1779-1785,

Benz, U.; Hofmann, P.; Willhauck, G.; Lingenfelder, I.; Heynen M. 2004. Multi-resolution, object-oriented fuzzy analysis of remote sensing data for GIS-ready information. ISPRS Journal of Photogrammetry and Remote Sensing, 58: 239-258. 
Cano-Crespo, A.; Oliveira, P.J.C.; Cardoso, M.; Thonicke, K. 2014. Tropical forest degradation in the Brazilian Amazon relation to fire Forest fires contribute to greenhouse-gas emissions. In: VIEGAS, D. X. (ED). Advances in forest fire research. Imprensa da Universidade de Coimbra.

Cochrane, M.A.; Schulze, M.D. 1993. Fire as a recurrent event in tropical forests of the eastern Amazon: effects on forest structure, biomass, and species composition. Biotropica 31: 2-16.

Fanin, T.; van der Werf, G. R. 2015. Relationships between burned area, forest cover loss, and land cover change in the Brazilian Amazon based on satellite data. Biogeosciences, 12: 6033-6043.

INPE. 2015. Amazon Program - Monitoring the Brazilian Amazon by satellite: The PRODES, DETER, DEGRAD and TerraClass Systems. Available at www.inpe.br (accessed 10 of May 2015).

Lima, A.; Silva, T.S.F.; Aragão, L.E.O.C.; Feitas, R.M.; Adami, M.; Formaggio, Antônio Roberto; Shimabukuro, Y.E. 2012. Land use and land cover changes determine the spatial relationship between fire and deforestation in the Brazilian Amazon. Appl. Geogr., 34:239-246.

Matricardi, E.A.T.; Skole, D.L.; Pedlowski, M.A.; Chomentowski, W.; Fernandes, L.C. 2010. Assessment of tropical forest degradation by selective logging and fire using Landsat imagery. Remote Sens. Environ., 114:1117-1129.

Miettinen, J.; Shimabukuro, Y.E.; Beuchle, R.; Grecchi, R.C.; Gomez, M.V.; Simonetti, D.; F., Achard. 2016. On the extent of fire-induced forest degradation in Mato Grosso, Brazilian Amazon, in 2000, 2005 and 2010. Int. J. Wildland Fire, 25:129136.

Morton, D.C.; Le Page, Y.; DeFries, R.; Collatz, G.J.; Hurtt, G.C. 2013. Understorey fire frequency and the fate of burned forests in Southern Amazonia,” Philos. Trans. Roy. Soc. B Biol. Sci., 368: 20120163.

Simonetti, D.; Marelli, A.; Eva H.D. IMPACT Toolbox, a Portable Open Source GIS Toolbox for Image Processing and Land Cover Mapping, Publications Office of the European Union, doi: 10.2788/143497. Last accessed: jun. 2016.

Shimabukuro, Y.E.; Smith, J.A. 1991. The least squares mixing models to generate fraction images derived from remote sensing multispectral data. IEEE Trans. Geosci. Remote Sens., 29:16-20.

Silva Monteiro, A.L.; Barreto, P.G.; Pantoja, F.L.D.S.; Gerwing, J.J. 2004. Impactos da exploração madeireira e do fogo em florestas de transição da Amazônia Legal. Scientia Forestalis, 65:11-21.

Souza, C.; Siqueira, J.; Sales, M.; Fonseca, A.; Ribeiro, J.; Numata, I.; Cochrane, M.; Barber, C.; Roberts, D.; Barlow, J. 2013. Ten-Year Landsat Classification of Deforestation and Forest Degradation in the Brazilian Amazon. Remote Sens., 511:5493-5513. 